BMJ Open

Diabetes

Research

\& Care

\title{
Changes in granule mobility and age contribute to changes in insulin secretion after desensitization or rest
}

\author{
Bastian Gaus, ${ }^{1}$ Dennis Brüning, ${ }^{1}$ Kathrin Hatlapatka, ${ }^{1,2}$ Ingo Rustenbeck ${ }^{1}$
}

To cite: Gaus B, Brüning D, Hatlapatka K, et al. Changes in granule mobility and age contribute to changes in insulin secretion after desensitization or rest. BMJ Open Diab Res Care 2021;9:e002394. doi:10.1136/ bmjdrc-2021-002394

\section{- Additional supplemental} material is published online only. To view, please visit the journal online (http://dx.doi. org/10.1136/bmjdrc-2021002394).

Received 18 May 2021 Accepted 14 September 2021

D) Check for updates

(C) Author(s) (or their employer(s)) 2021. Re-use permitted under CC BY-NC. No commercial re-use. See rights and permissions. Published by BMJ.

${ }^{1}$ Department of Pharmacology, Toxicology and Clinical Pharmacy, Technische Universität Braunschweig, Braunschweig, Germany ${ }^{2}$ DHD-Consulting GmbH, Hildesheim, Germany

Correspondence to Dr Ingo Rustenbeck; i.rustenbeck@tubraunschweig.de

\section{ABSTRACT}

Introduction Functional impairment of the stimulus secretion coupling in pancreatic beta cells is an essential component of type 2 diabetes. It is known that prolonged stimulation desensitizes the secretion of insulin and thus contributes to beta cell dysfunction. Beta cell rest, in contrast, was shown to enhance the secretory response. Here, the underlying mechanisms were investigated. Research design and methods To characterize the consequences of desensitization or rest for the number and mobility of submembrane granules, insulin-secreting MIN6 cells were desensitized by 18-hour culture with $500 \mu \mathrm{M}$ tolbutamide or rested by 18-hour culture with $1 \mu \mathrm{M}$ clonidine. The granules were labeled by hIns-EGFP or hlns-DsRed E5, imaged by TIRF microscopy of the cell footprint area and analyzed with an observer-independent program. Additionally, the insulin content and secretion were measured.

Results Concurrent with the insulin content, submembrane granules were only slightly reduced after desensitization but markedly increased after rest. Both types of pretreatment diminished arrivals and departures of granules in the submembrane space and increased the proportion of immobile long-term resident granules, but desensitization lowered and rest increased the number of exocytoses, in parallel with the effect on insulin secretion. Labeling with hlns-DsRed E5 ('timer') showed that desensitization did not affect the proportion of aged granules, whereas rest increased it. Aged granules showed a high mobility and made up only a minority of long-term residents. Long-term resident granules were more numerous after rest and had a lower lateral mobility, suggesting a firmer attachment to the membrane.

Conclusion The number, mobility and age of submembrane granules reflect the preceding functional states of insulin-secreting cells. Representing the pool of releasable granules, their quantity and quality may thus form part of the beta cell memory on renewed stimulation.

\section{INTRODUCTION}

Decades ago, it was noted that the prolonged stimulation of insulin secretion by KATP channel blocking sulfonylureas, such as tolbutamide or glibenclamide, diminishes the efficiency of a subsequent insulinotropic stimulus. ${ }^{1-3}$ Later investigations clarified that overnight culture of isolated islets in a maximally effective concentration of a sulfonylurea

\section{SIGNIFICANCE OF THIS STUDY \\ WHAT IS ALREADY KNOWN ABOUT THIS SUBJECT? \\ $\Rightarrow$ Recent evidence suggests that functional impair- ment of the beta cell dominates over beta cell loss in the pathogenesis of type 2 diabetes. This im- pairment, which is in principle reversible, can be produced by prolonged stimulation of secretion. However, prolonged inhibition of insulin secretion has been shown to increase the secretory response on restimulation. The underlying mechanisms are not fully understood.}

\section{WHAT ARE THE NEW FINDINGS?}

$\Rightarrow$ Prolonged stimulation by depolarization had only a minor diminishing effect on the number of submembrane granules and insulin content.

$\Rightarrow$ Prolonged inhibition of secretion had a major increasing effect on the number of submembrane granules and insulin content.

$\Rightarrow$ Even though the granule turnover in the submembrane space was slowed after either pretreatment, exocytoses and secretion were diminished after prolonged stimulation and increased after prolonged inhibition of secretion.

$\Rightarrow$ Even though the prolonged inhibition of secretion increased the content of aged granules, which show enhanced mobility, it also resulted in a high portion of granules with longer residence at the plasma membrane, increasing the probability of release.

\section{HOW MIGHT THESE RESULTS CHANGE THE} FOCUS OF RESEARCH OR CLINICAL PRACTICE?

$\Rightarrow$ It is known that insulin secretion is determined by the acute condition of stimulation and by the metabolic memory of the beta cells. The metabolic memory consists, at least in part, in the number and mobility of submembrane granules. In addition to the determination of the granule fusion frequency, the quantitative description of the granule dynamics prior to fusion will give deeper insight into the regulation of stimulus secretion coupling.

reduced the response to nutrient stimuli as well as to purely depolarizing stimuli. ${ }^{4}$ The low specificity of the desensitization could be 
caused by functional changes at late steps of signal transduction and/or the diminished availability of releasable insulin. Measurements of immunoreactive insulin after desensitization have mostly shown moderate reductions (by $10 \%-30 \%$ ) of insulin content, ${ }^{5-7}$ whereas electron microscopy reported more marked reductions of the granulation state. ${ }^{4}$

The observations that an increased workload imposed on the beta cell leads to a diminished secretory response on restimulation is complemented by observations in vitro and in vivo that phases of reduced workload or of outright inhibition of secretion do increase the islet insulin content and enhance the secretory response to a subsequent stimulus. ${ }^{8-10}$ Therefore, the induction of temporary beta cell rest as a means to improve the secretion profile was clinically tested by using the opener of KATP channels, diazoxide. Even though positive effects on beta cell function were obtained, the improvement of metabolic control that could be reached without risking systemic side effects was modest. ${ }^{112}$ Again, the question is by which mechanism(s) the secretory response reflects the preceding functional state.

It is well known that only a minority of the insulin granules are fusion competent ${ }^{13}$ and that the condition prevailing at the time of granule biogenesis affects their probability of exocytosis. ${ }^{14}$ The TIRF microscopy of fluorescently labeled insulin granules together with a quantitative evaluation of image sequences permits detailed insight into the fusion of insulin granules and the preexocytotic fate. ${ }^{14-17}$ To explore the consequences of beta cell desensitization and beta cell rest, we analyzed their number, mobility, fusion rate and age in insulin-secreting MIN6 cells, which had been exposed to maximally effective concentrations of the sulfonylurea, tolbutamide or the alpha $_{2}$-adrenoceptor agonist, clonidine. MIN6 cells were chosen as the experimental model since the observed changes at the single cell level can be expected to correlate more closely with the changes in secretion of homogeneous MIN6 cell populations than changes in single primary beta cells reflect the secretion of perifused normal islets. ${ }^{18} 19$

\section{RESEARCH DESIGN AND METHODS}

\section{Chemicals}

DMEM cell culture medium and fetal bovine serum (FCS Gold Add) were from GIBCO-Life technologies (Darmstadt, Germany) and from Bio \& Sell (Feucht, Germany), respectively. Tolbutamide and clonidine were obtained from Sigma (Taufkirchen, Germany). All other reagents of analytical grade were from E. Merck (Darmstadt, Germany).

\section{Cell culture, plasmid construction and transfection}

The insulin granules of MIN6 cells (p20-p30) were labeled by transient transfection with hIns-EGFP or hIns-DsRed E5 (DsRed E5 is also named 'timer'). Then, the transfection medium was removed and replaced by
DMEM $(25 \mathrm{mM}$ glucose, the standard glucose concentration for the culture of MIN6 cells, ref 20) or DMEM plus $500 \mu \mathrm{M}$ tolbutamide (beta cell desensitization) or DMEM plus $1 \mu \mathrm{M}$ clonidine (beta cell rest) for 18 hours. MIN6 pseudoislets ${ }^{21}$ were generated by culturing MIN6 cells under the conditions described previously. The formation of pseudoislets was enhanced by using dishes for suspension cell culture. Ten days were usually needed to obtain pseudoislets of sufficient size (for details see online supplemental file).

\section{TIRF microscopy (TIRFM)}

After cell culture, the cells were washed twice with HEPES-buffered Krebs-Ringer medium (composition: $115 \mathrm{mM} \mathrm{NaCl}, 4.7 \mathrm{mM} \mathrm{KCl}, 2.6 \mathrm{mM} \mathrm{CaCl}, 1.2 \mathrm{mM}$ $\mathrm{KH}_{2} \mathrm{PO}_{4}, 1,2 \mathrm{mM} \mathrm{MgSO}, 20 \mathrm{mM} \mathrm{NaHCO}$ and $10 \mathrm{mM}$ HEPES). The cover slip on which the cells had grown was fixed to a purpose-made perifusion chamber on the programmable stage of an iMIC microscope (Till Photonics, Gräfelfing, Germany). The basal glucose concentration of the Krebs-Ringer medium was $3 \mathrm{mM}$ glucose; it was prewarmed and equilibrated with $95 \% \mathrm{O}_{2}$ and $5 \% \mathrm{CO}_{2}$ before reaching the environmental control chamber of the microscope. The flow rate was $200 \mu \mathrm{L} /$ min. Fluorescence of hIns-EGFP or hIns-DsRed E5 in the evanescent field was excited by a $491 \mathrm{~nm}$ laser. The green emission of hIns-DsRed E5 was separated from the red at $560 \mathrm{~nm}$. The exposure time was $50 \mathrm{~ms}$ per image, the cycle time for acquisition and storage was $125 \mathrm{~ms}$ (for details, see online supplemental file). The fluorescence of the hIns-EGFP-labeled or hIns-DsRed E5-labeled granules was identified, and the mobility of the resulting spots during sequences of 200 images each was analyzed by a purpose-written program (for details, see ref 22).

\section{Granule tracking}

During an equilibration period of $45 \mathrm{~min}, 8-12$ cells were characterized by acquiring one sequence of 200 images per cell. Thereafter, the response to glucose perifusion or $\mathrm{KCl}$ perifusion was characterized by selecting an area with two or three newly identified cells in the field of view and acquiring eight sequences of 200 images each prior to or during the stimulation. The granule number at the beginning of each sequence was counted as was the number of all granules that were newly identified during the sequence. The different dwell time in the submembrane space was described by counting the granules with a presence for eight images or less, equivalent to $\leq 1 \mathrm{~s}$ (short-term residents) and those that were present throughout the entire sequence, equivalent to $\geq 25 \mathrm{~s}$ (long-term residents). The granule mobility orthogonal to the plasma membrane was described by the number of arrivals at and departures from the submembrane space, and the mobility parallel to the plane of the membrane was described by the caging diameter (for details, see online supplemental file). 
Spinning disk confocal laser scanning microscopy

To acquire z-stack images of MIN6 cells transfected with hIns-DsRed E5 during a static incubation, a cover slip with the attached cells was pasted on a cavity glass slide filled with Krebs-Ringer medium ( $3 \mathrm{mM}$ glucose). The slide was placed upside down on the stage of an inverted Nikon Ti2-E microscope equipped with a Nikon CFI SR HP Apochromat objective (100×, 1.49 N.A.). Fluorescence excitation was at $491 \mathrm{~nm}$ and passed a Yokogawa CSU W1 SORA spinning disk unit; the resulting fluorescence emission was separated at $560 \mathrm{~nm}$ and directed at two sCMOS cameras (Photometrics Prime BSI). The instrument control and image generation was performed by Visiview Premier software (Visitron Systems, Munich, Germany).

\section{Viability of MIN6 cells after desensitization or rest}

The relation of live and dead cells was assessed by the live/dead assay according to the manufacturer's protocol (PromoCell, Heidelberg, Germany). The number of living cells was determined by the green fluorescence of calcein. The calcein AM-ester is membrane permeable but non-fluorescent; the ester cleavage in the cytosol of living cells results in a green fluorescence, provided the plasma membrane is intact and retains the fluorophore. The number of dead cells is determined by the red fluorescence of ethidium homodimer III. This compound is excluded from cells with an intact plasma membrane but can reach the nucleus of dead cells. The binding to nuclear DNA increases the fluorescence about 40-fold. After loading with the indicators, Petri dishes with glass bottom (ibidi GmbH, Gräfelfing, Germany) were placed on the stage of an inverted Nikon Ti2-E microscope fitted with a Yokogawa CSU W1 spinning disk unit as described previously. The green fluorescence was excited at $491 \mathrm{~nm}$ and the red fluorescence at $561 \mathrm{~nm}$ and collected by a Nikon S Fluor (40×, 1.3 N.A.) objective.

\section{Microfluorimetric measurements of the cytosolic $\mathrm{Ca}^{2+}$ concentration $\left(\left[\mathrm{Ca}^{2+}\right]_{\mathrm{i}}\right)$}

MIN6 cells and MIN6 pseudoislets were loaded at $32^{\circ} \mathrm{C}$ with Fluo4/AM at a concentration of $1 \mu \mathrm{M}$ for $20 \mathrm{~min}$. The cover slip with the attached cells or pseudoislets was inserted into a purpose-made thermostated perifusion chamber, placed on the stage of an Axiovert microscope (Zeiss, Jena, Germany). The cells were perifused with HEPES-buffered Krebs-Ringer medium, which was continuously gassed with a mixture of $95 \% \mathrm{O}_{2}$ and $5 \% \mathrm{CO}_{2}$. The fluorescence (excitation at $490 \mathrm{~nm}$, emission $>510 \mathrm{~nm}$ ) was recorded by a cooled CCD camera (Pursuit, Diagnostics Instruments, Sterling Heights, Michigan, USA) under control of VisiView Software (Visitron, Munich, Germany).

\section{Insulin secretion}

Insulin secretion during the periods of desensitization or rest was measured by aspiration of the cell culture medium, centrifugation to sediment detached cells and measuring the insulin content by ELISA (Mercodia, Uppsala, Sweden). The same procedure was followed to measure insulin after short-term static incubations in Krebs-Ringer medium (see above, plus $2 \mathrm{mg} / \mathrm{mL}$ BSA) saturated with $95 \% \mathrm{O}_{2}$ and $5 \% \mathrm{CO}_{2}$. For the measurement of the kinetics of secretion batches of 200 MIN6 pseudoislets were introduced into a thermostated perifusion chamber and perifused with Krebs-Ringer medium (for details, see ref 23). The insulin content in the fractionated efflux was determined by ELISA. The islet insulin content was measured by sonicating a group of 30 pseudoislets in an ice-cooled microtube for $20 \mathrm{~s}$ and measuring the insulin concentration after appropriate dilution with the zero buffer of the ELISA set.

\section{Statistics}

GraphPad Prism V.5 software (GraphPad, LaJolla, California, USA) was used for statistic calculations and nonlinear curve fitting. If not stated otherwise, 'significant' refers to $\mathrm{p}<0.05$, 't-test' to the unpaired, two-sided t-test and 'ANOVA' stands for the one-way analysis of variance (ANOVA).

\section{RESULTS}

To ensure that $500 \mu \mathrm{M}$ tolbutamide had established a desensitized state and $1 \mu \mathrm{M}$ clonidine had established a resting state, the insulin released into the culture medium during the 18-hour culture period was measured. The control value was $17.5 \pm 1.1 \mathrm{pg}$ per min and 1000 cells. Both tolbutamide and clonidine significantly (ANOVA with Dunnett's post-test) decreased the amount of insulin released during the exposure period, tolbutamide by 22 $\%$ and clonidine by $69 \%$. The viability was not affected by exposure to the drugs (for details, see online supplemental file).

The initial measurements of granule number and mobility showed that the cell footprint was moderately but significantly smaller $\left(262 \pm 16\right.$ vs $\left.332 \pm 27 \mu \mathrm{m}^{2}\right)$ after desensitization by tolbutamide than after control culture (figure 1A). Therefore, all evaluations were normalized to a footprint area of $200 \mu^{2}$. The number of submembrane granules per time point (simply denoted as granule number) was not significantly different between tolbutamide-cultured and control-cultured MIN6 cells. However, when all granules that appeared during the acquisition of the entire sequence of 200 images were added up (cumulative granule number), the value for tolbutamide-cultured cells was significantly smaller than for control-cultured cells (figure 1B).

After culture in the presence of clonidine to induce beta cell rest, a similar size difference existed, even though MIN6 cells of this passage number were markedly larger ( $362 \pm 30$ vs $499 \pm 36 \mu^{2}$, figure $\left.1 \mathrm{~A}\right)$. In contrast to tolbutamide-cultured cells, the number of submembrane granules was significantly higher than after control culture (figure 1B), but the cumulative number of submembrane granules was again significantly smaller 


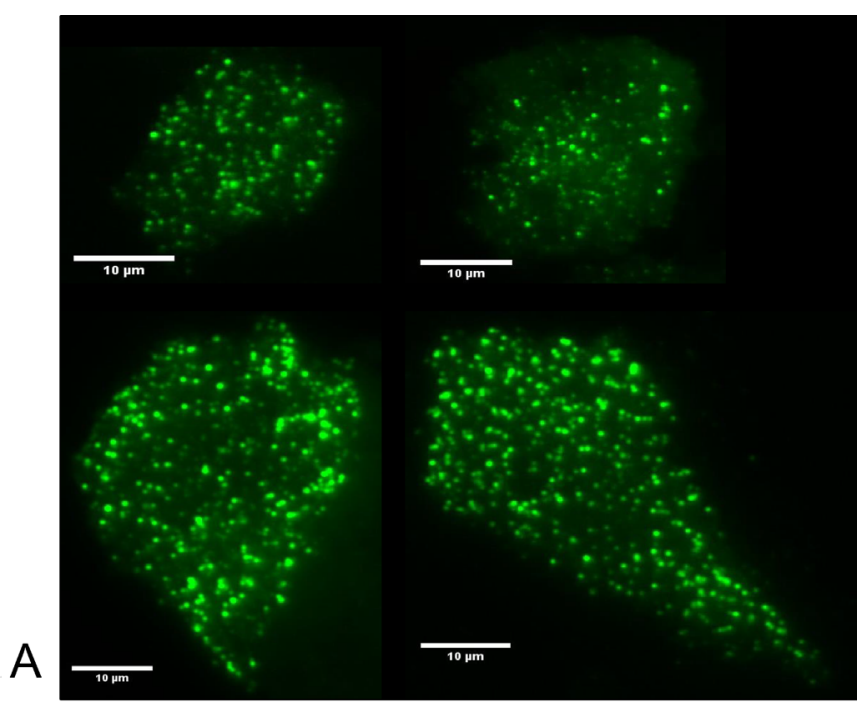

by a decreased lateral mobility (expressed as the caging diameter, figure 1B).

After the initial assessment, two or three newly identified cells were followed up during the perifusion with stimuli by acquiring sequences of 200 images each at eight characteristic time points (figure 2). In response to glucose, but not $\mathrm{KCl}$, stimulation the granule number of control-cultured MIN6 cells decreased. Moderate but significant increases by stimulation existed in the cumulative number of granules, short-term residents and arriving granules, whereas the long-term resident granules and the caging diameter did not show stimulationrelated changes.

After desensitization, the previous mobility pattern was shifted in parallel. The shift was to lower numbers with the cumulative granules, short-term residents and arriving granules and, conversely, to higher numbers with the long-term residents. The latter feature fits to the markedly diminished caging diameter. As in the initial assessment, the number of granules was not different between test and control, except for the duration of glucose stimulation (figure 2A).

The response of the clonidine-cultured, rested MIN6 cells and their respective controls to the insulinotropic stimuli was more vigorous but followed essentially the same pattern (figure 2B). Like after tolbutamide culture, the cumulative number of granules was lower than in control cells, as was the number of short-term residents and granule arrivals. The number of long-term resident granules was significantly higher, which was again accompanied by a diminished caging diameter. The number of granules per time point, which was initially higher than in control-cultured cells (see figure 1B), diminished in the course of the perifusion and was finally significantly lower.

The relation between residence and lateral mobility was investigated by dividing the entirety of the submembrane granules into subpopulations with different periods of residence. A clear inverse relation between residence and mobility emerged, but in all subpopulations, the caging diameter was significantly smaller in drug-exposed than in control MIN6 cells (figure 3A). Interestingly, the twoway ANOVA noted an interaction between clonidine culture and control, but not between tolbutamide-culture and control, suggesting that the gradual reduction of the caging diameter followed a different time course after beta cell rest.

The tolbutamide-cultured cells showed a consistently lower number of exocytoses than their control-cultured cells; neither of these responded to glucose or KCl. The clonidine-cultured MIN6 cells showed a higher number of exocytoses than their controls in response to the stimuli (figure 3B). In both cases, the difference between treatment and control was highly significant.

The granule age as a possible factor contributing to the altered mobility pattern after desensitization or beta cell rest was investigated by using MIN6 cells transfected with hIns-DsRed E5 (hIns-'timer'), which changes its emission granules that were present from the first to the last image of the sequence (long-term residents) was higher after exposure to either drug; this feature was accompanied 

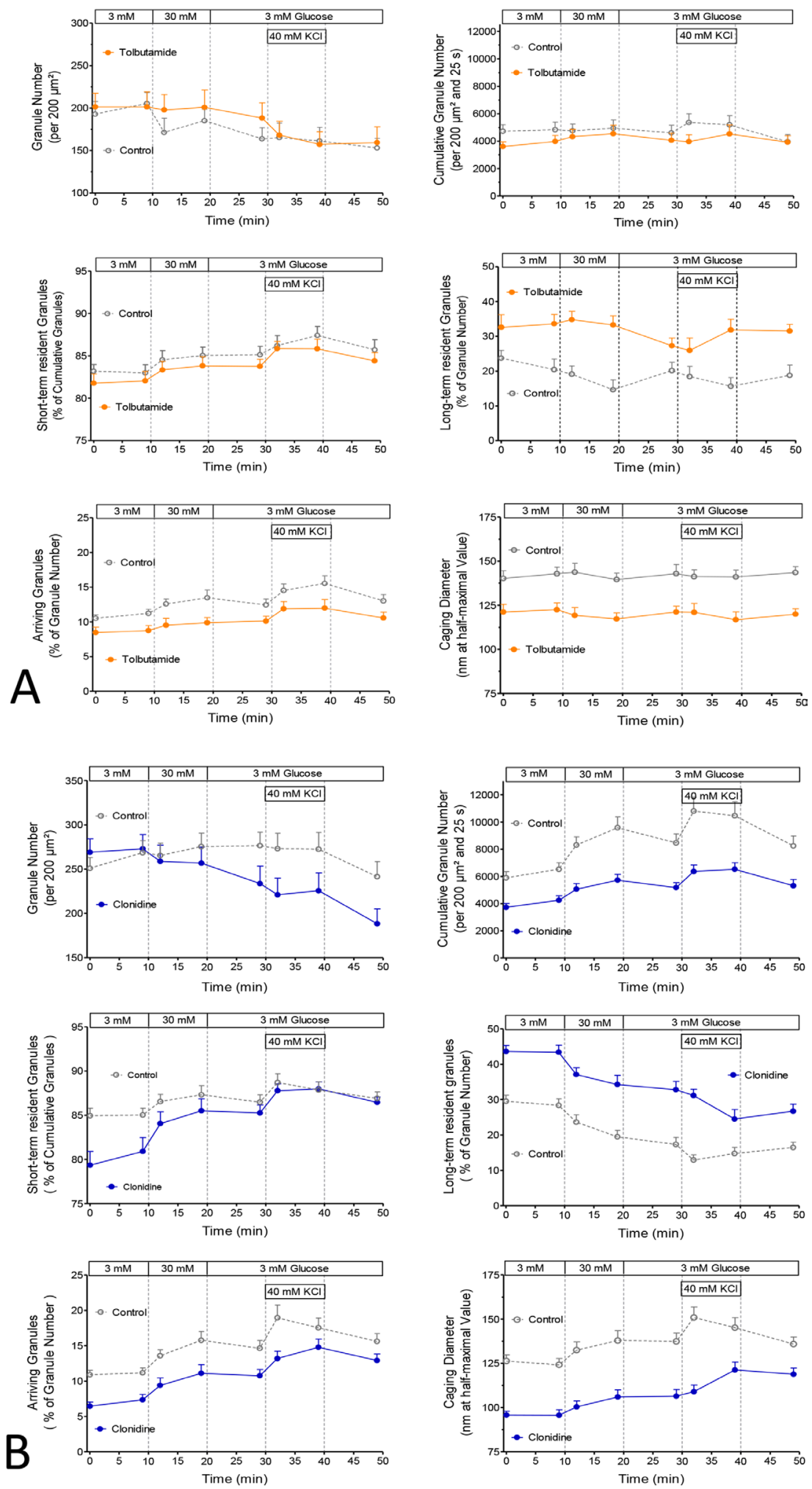

Figure 2 Stimulation-induced changes of submembrane insulin granule number and mobility after beta cell desensitization or rest. At characteristic time points during a $50 \mathrm{~min}$ perifusion, eight sequences of 200 images each were acquired and analyzed. The graphs show the number of granules in the first image of a sequence (upper left), the cumulative number of granules identified during the entire sequence (upper right), the number of granules that were present for up to one second (short-term residents, middle left), the number of granules that were present for the entire length of the sequence (long-term residents, middle right), the number of arriving granules per sequence (lower left) and the lateral mobility (expressed as the caging diameter, lower right). (A) Comparison of MIN6 cells cultured in the presence of $500 \mu \mathrm{M}$ tolbutamide with paired controlcultured MIN6 cells. Values are means \pm SEM of 17 (tolbutamide) or 14 (control) cells from six experiments each. (B) Comparison of MIN6 cells cultured in the presence of $1 \mu \mathrm{M}$ clonidine with paired control-cultured MIN6 cells. Values are means \pm SEM of 13 (clonidine) or 15 (control) cells from six experiments each. 

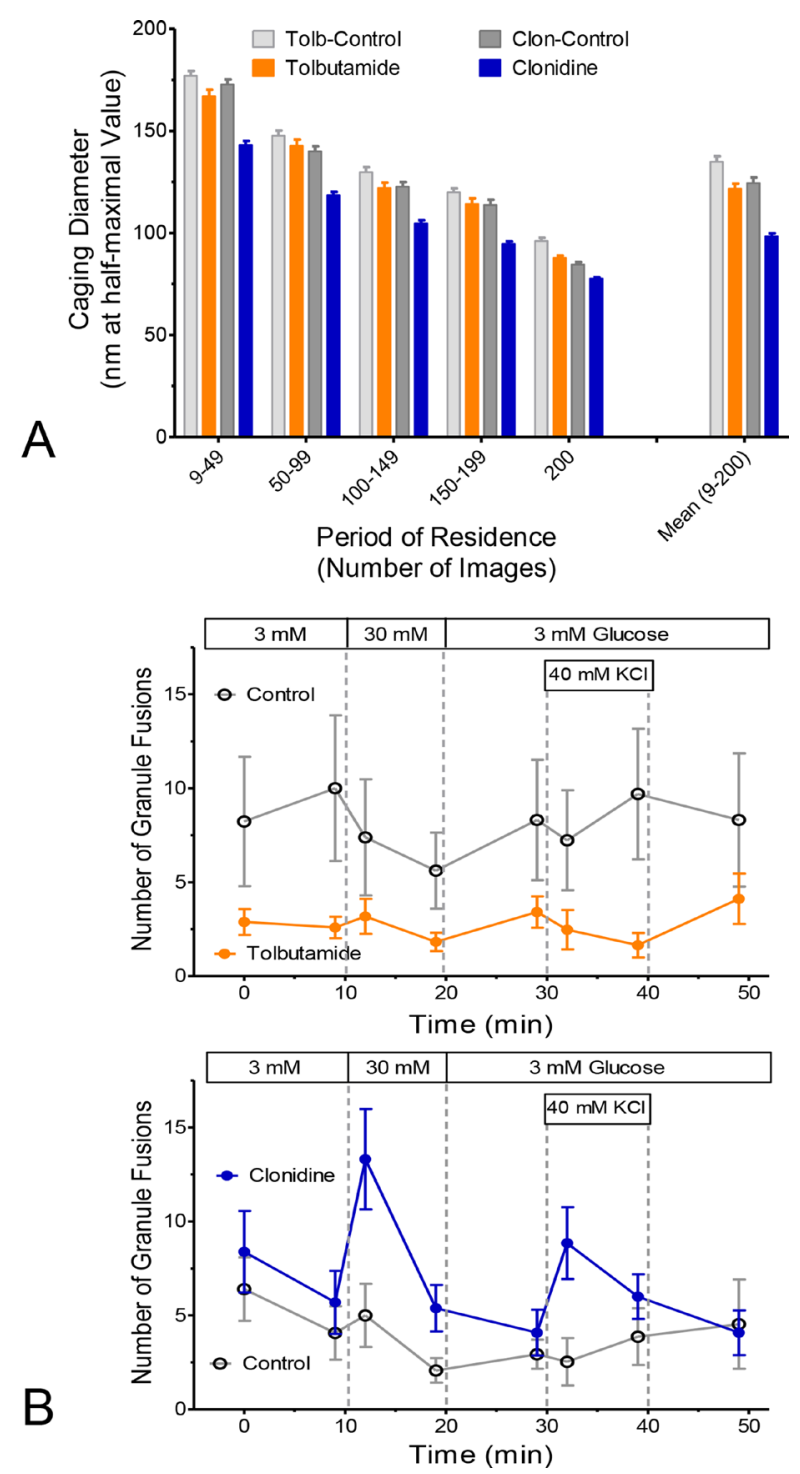

Figure 3 Granule attachment and fusion after beta cell desensitization or rest. (A) All granules that were present in the submembrane space for more than $1 \mathrm{~s}$ were subdivided into five groups with increasing periods of residence. The effects of treatment (tolbutamide or clonidine) and of time period were highly significant $(p<0.001$, two-way analysis of variance (ANOVA)). Values are means \pm SEM of 52 (tolbutamide and controls) or 60 (clonidine and controls) cells each. (B) Diminished granule fusions after desensitization by tolbutamide (orange symbols, upper graph) but increased fusions after rest by clonidine (blue symbols, lower graph). The effect of treatment was highly significant in both cases $(p<0.001)$, whereas the effect of time was only significant for clonidine $(p<0.01$, two-way ANOVA). Values are means \pm SEM of 17 (tolbutamide) or 14 (control) cells from six experiments each and of 13 (clonidine) or 15 (control) cells from six experiments each.

from green to red via a yellow/orange transition state. In these experiments, the beta cell desensitization and beta cell rest were induced in parallel with one control culture. The hIns-DsRed E5 label caused more mistargeting than the hIns-EGFP label (figure 4A), but a clear identification
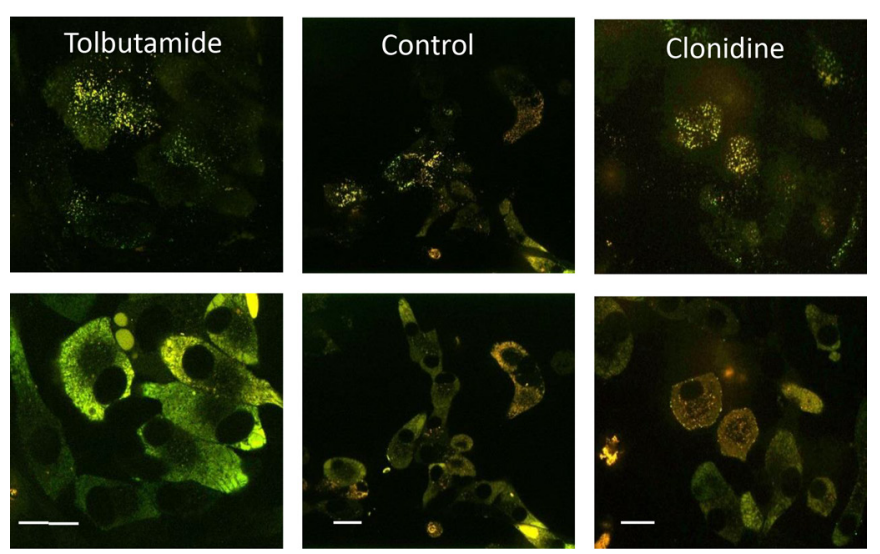

A
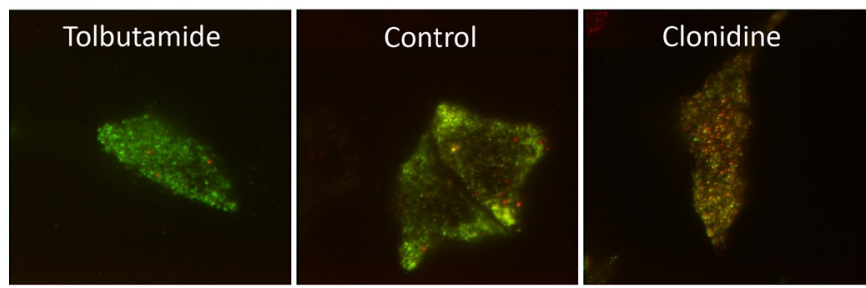

B

Figure 4 Aspect of granulation state and size of MIN6 cells labeled with hlns-dsRed E5. (A) MIN6 cells labeled with hInsdsRed E5 were cultured for 18 hours either in the presence of $500 \mu \mathrm{M}$ tolbutamide (left) or $1 \mu \mathrm{M}$ clonidine (right) or control cultured (middle) and imaged by SD-CLSM close to the plasma membrane $(0.2 \mu \mathrm{m}$, upper row) or close to the cell middle $(4 \mu \mathrm{m}$, lower row). Note the considerable mistargeting and heterogeneous appearance. The length of the bars is $10 \mu \mathrm{m}$. (B) In the TIRF mode, a clear identification of single granules was possible after culture in the presence of tolbutamide or clonidine or after control culture. The different ratio of green to red fluorescence is clearly visible. Note the presence of red granules in the submembrane space. SDCLSM, spinning disk confocal laser scanning microscopy.

of granules in the cell periphery was possible, enabling the quantitative evaluation by TIRFM (figure 4B).

Independent of the culture condition, the number of young granules in the submembrane space was higher than the one of aged granules (figure 5), but the ratio of young to old granules was significantly higher after tolbutamide culture than after clonidine culture. The same applied to the cumulative number of granules. The value of the green/red ratios was often higher than appears from the number of the green and red granules. This was true for the granule number, the cumulative granule number and the long-term residents. This discrepancy resulted from particularly high ratios in cells with low granule numbers.

The parameters specifically describing the mobility, namely the short-term residents, the arriving granules (z-dimension) and the caging diameter (x/y dimension) all showed higher values for aged than for young 

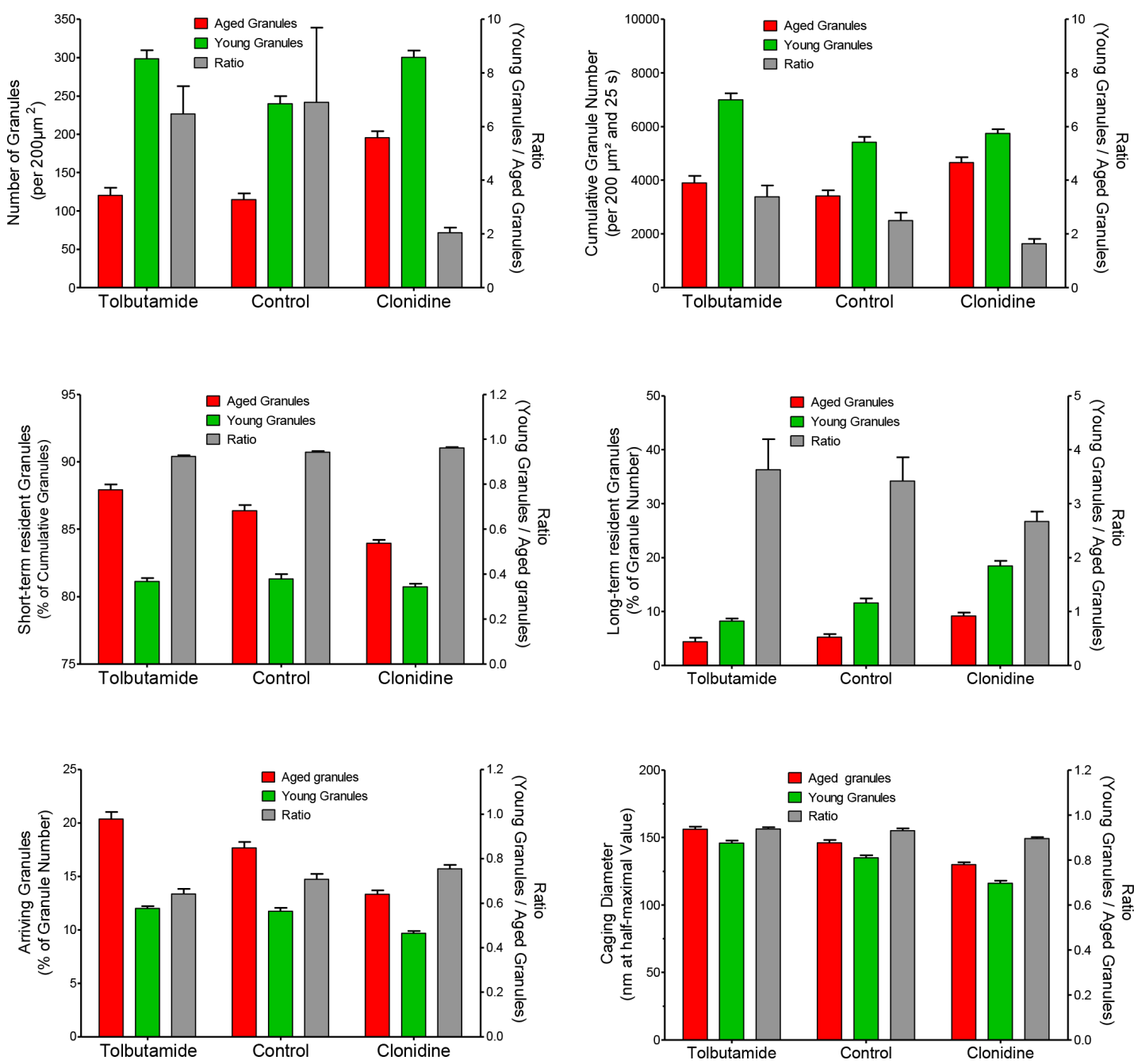

Figure 5 Assessment by TIRFM of insulin granule number and mobility in the submembrane space of MIN6 cells labeled with hlns-dsRed E5. The cells were cultured for 18 hours either in the presence of $500 \mu \mathrm{M}$ tolbutamide or $1 \mu \mathrm{M}$ clonidine or control cultured. The granules are subdivided in young (green bars) and old (red bars) granules; the ratio of young/old is given by gray bars. The graphs show the number of granules in the first image of a sequence (upper left), the cumulative number of granules identified during one sequence (upper right), the number of granules that were present for up to $1 \mathrm{~s}$ (short-term residents, middle left), the number of granules that were present throughout the entire sequence (long-term residents, middle right), the number of arriving granules (lower left) and the lateral mobility (caging diameter, lower right). Values are means \pm SEM of 92 (tolbutamide), 95 (control) or 118 (clonidine) cells from six experiments each. TIRFM, TIRF microscopy.

granules; the arrivals most clearly so (figure 5). Again, the effects of desensitization and rest are best demonstrated by the green/red ratio: with arriving granules and short-term residents, this parameter increased in the sequence tolbutamide $<$ control $<$ clonidine $(\mathrm{p}<0.001$, ANOVA), whereas with the caging diameter, it decreased in this sequence $(\mathrm{p}<0.001$, ANOVA, figure 5 ). Independent of granule age clonidine culture led to a higher number of long-term residents than control culture which, in turn, led to a higher number than tolbutamide culture $(p<0.001$, ANOVA, figure 5).

Static incubation of single MIN6 cells was used to assess the effects of desensitization and rest on insulin secretion (figure 6A). Clonidine-cultured MIN6 cells had a higher secretion than control during glucose and $\mathrm{KCl}$ stimulation, whereas the secretion of tolbutamidecultured cells was lower than control during $\mathrm{KCl}$ stimulation. The sequence of clonidine-cultured cells $>$ controls > tolbutamide-cultured cells remained unaltered after correction for the different basal secretion (figure $6 \mathrm{~B}$ ).

Perifused MIN6 pseudoislets were used to better characterize the effects of desensitization and rest on glucose stimulation. The increase caused by $30 \mathrm{mM}$ glucose was moderate in control pseudoislets and even less in pseudoislets cultured in the presence of either drug. The depolarization by $40 \mathrm{mM} \mathrm{KCl}$ caused much larger secretory responses (figure 6C). Here, the secretion by clonidine-cultured pseudoislets was about $60 \%$ (area-under-the curve (AUC)) of the control value, which was not significantly different, in contrast to the $26 \%$ of control (AUC) by tolbutamide-cultured pseudoislets. Normalizing the initial values to $100 \%$ revealed the sluggish onset of glucose-stimulated secretion both 

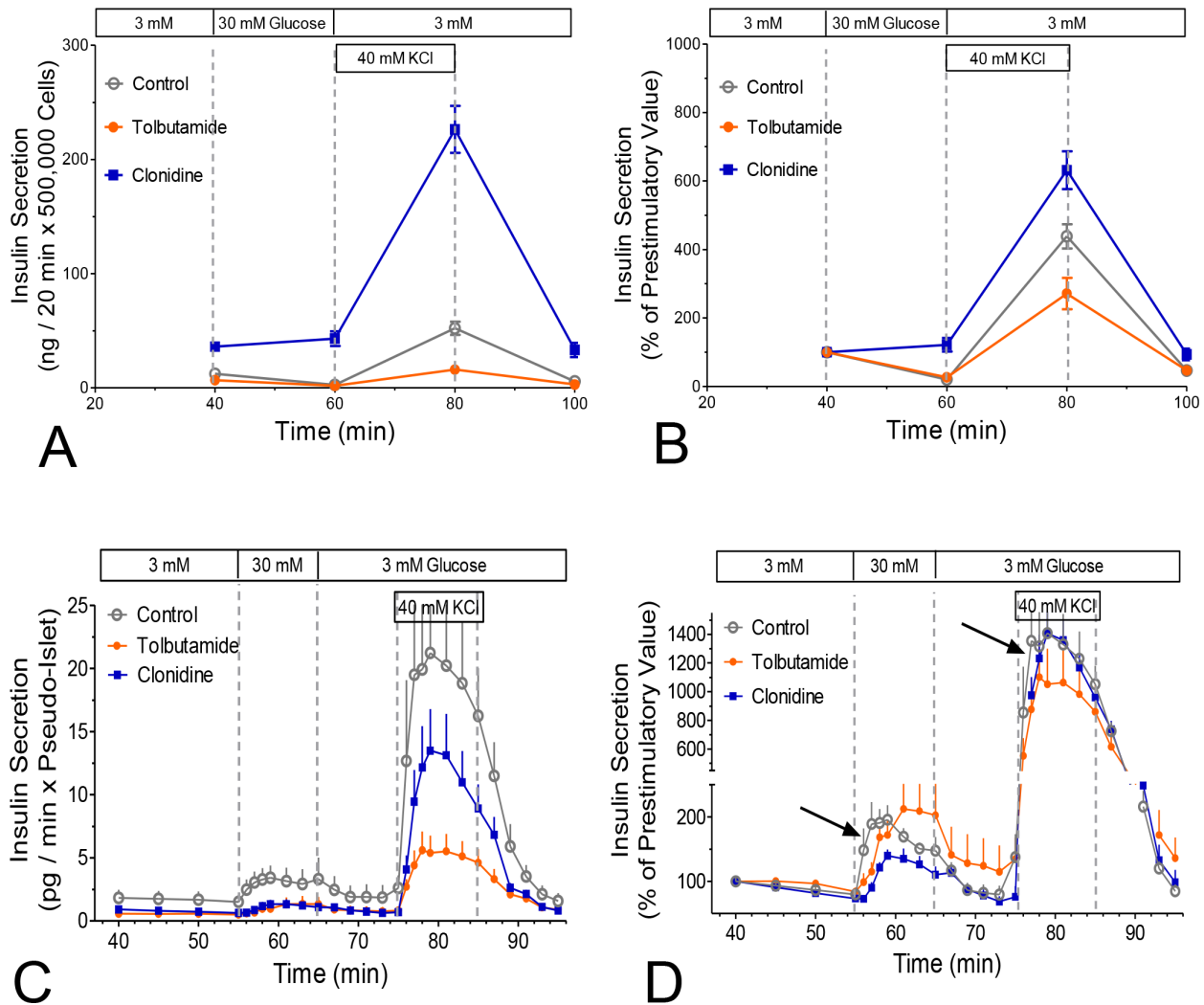

Figure 6 Effects of beta cell desensitization or rest on the insulin secretion by MIN6 cells. (A) Insulin secretion during static incubation of single MIN6 cells after tolbutamide culture (orange-filled circles), control culture (grey open circles) and clonidine culture (blue squares). Note the increased response to $\mathrm{KCl}$ by clonidine-cultured cells and the diminished response to $\mathrm{KCl}$ by tolbutamide-cultured cells. (B) This pattern remains visible when the secretion is expressed as \% of last prestimulatory value. Values are means \pm SEM from eight experiments each. (C) Insulin secretion of MIN6-pseudoislets after tolbutamide culture (orange-filled circles), control culture (grey open circles) and clonidine culture (blue squares). Tolbutamide and clonidine culture diminished the secretory response to $30 \mathrm{mM}$ glucose, but only tolbutamide significantly diminished the response to $40 \mathrm{mM} \mathrm{KCl}$ $(p<0.05 \mathrm{vs}$ control, analysis of variance with Bonferroni correction). The secretion is expressed as pg per min and pseudoislet; values are means \pm SEM of six experiments each. (D) Same data as in part $C$ but expressed as \% of last prestimulatory value $(55 \mathrm{~min})$. Note the slower increase in response to glucose and $\mathrm{KCl}$ of islets exposed to either drug.

after tolbutamide culture and after clonidine-culture (figure 6D).

The insulin content of clonidine-cultured pseudoislets was more than double the content of control-cultured pseudoislets, whereas tolbutamide-cultured pseudoislets showed a moderate but significant reduction by nearly $30 \%$.

In view of the difference between perifused MIN6pseudoislets and statically incubated MIN6 cells, the cytosolic $\mathrm{Ca}^{2+}$ concentration $\left(\left[\mathrm{Ca}^{2+}\right]_{\mathrm{i}}\right)$ during stimulation was measured in both preparations. Compared with controls, tolbutamide-cultured pseudoislets showed an elevated basal level and diminished increases of $\left[\mathrm{Ca}^{2+}\right]_{i}$ on stimulation, whereas clonidine-cultured pseudoislets showed an unchanged basal level with augmented increases (figure 7 ). The $\left[\mathrm{Ca}^{2+}\right]_{i}$ of control single MIN6 cells increased slightly in response to glucose and much more vigorously in response to $\mathrm{KCl}$. Compared with controls, tolbutamide-cultured cells showed a higher basal $\left[\mathrm{Ca}^{2+}\right]_{i}$ level and no discernible increase in response to glucose but a strongly enhanced response to $\mathrm{KCl}$. The $\left[\mathrm{Ca}^{2+}\right]_{i}$ of clonidine-cultured cells showed essentially the same characteristics; however, the enhanced response to $\mathrm{KCl}$ was less marked than in tolbutamide-cultured cells.

\section{DISCUSSION}

While the fusion of the insulin granules with the plasma membrane is the subject of detailed investigations (see, eg, refs 151724 ), the preceding fate of the granules has obtained less attention. However, in which quantity and in which state the insulin granules arrive at the plasma membrane may define the number of granules that can respond to the $\mathrm{Ca}^{2+}$ signal for granule fusion and, in consequence, the strength of secretion.

Actually, the limited number of secretion-ready granules is a widely accepted explanation for the transient nature of the first phase of glucose-induced insulin secretion. ${ }^{25}{ }^{26}$ The idea that insulin granules consist of distinct pools, a readily releasable pool and a more distant reserve pool, was inspired by the neuronal exocytosis. The much lower rate of granule fusion as compared with the fusion rate of neurotransmitter vesicles ${ }^{27}$ makes the number of 

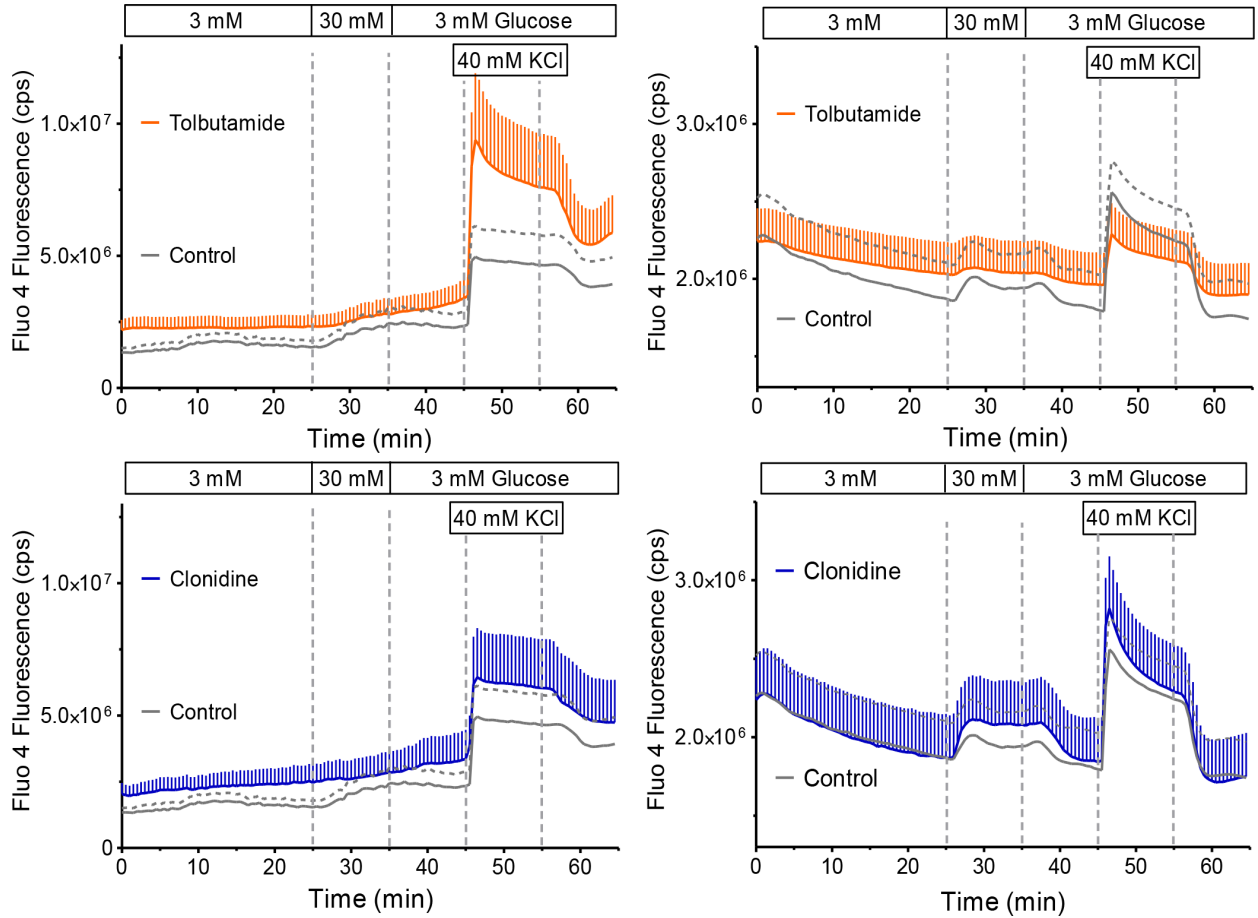

Figure 7 Effects of beta cell desensitization or rest on the cytosolic $\mathrm{Ca}^{2+}$ concentration $\left(\left[\mathrm{Ca}^{2+}\right]_{\mathrm{j}}\right)$. Fluo4-loaded MIN6 pseudoislets (right panels) or single MIN6 cells (left panels) were perifused with Krebs-Ringer medium containing $3 \mathrm{mM}$ glucose. From 25 to $35 \mathrm{~min}$, the glucose concentration was $30 \mathrm{mM}$; from 45 to $55 \mathrm{~min}$, the $\mathrm{KCl}$ concentration was $40 \mathrm{mM}$. The fluorescence of three to five pseudoislets or of 10-15 cells was measured per experiment. The trace of the tolbutamidecultured pseudoislets or cells (orange) is shown superimposed on the one of controls (gray) in the upper panels; in the lower panels, the trace of the clonidine-cultured pseudoislets or cells (blue) is shown superimposed on the same controls (gray). Values are mean \pm SEM of five to seven experiments.

secretion-ready granules per time point less limiting for the strength of secretion. It has been shown earlier that the size of the first phase can be much expanded by the addition of stimuli with different mechanisms of action. ${ }^{28}$

Insulin secretion rates are often expressed as percentage of the insulin content (eg, ref 29), assuming that the content reflects the granules available for secretion. Actually, we found the effects of beta cell desensitization or rest on the insulin content to be reflected by the number of submembrane granules. The increase of granule number and insulin content by constant inhibition of secretion appears plausible, but the very limited decrease by longterm tolbutamide stimulation may seem illogical, since purely depolarizing stimuli like sulfonylureas do not increase insulin and granule biosynthesis. ${ }^{30} 31$ However, the present measurement of the insulin content in the cell culture medium, which was decreased by clonidine and by tolbutamide, concurs with the earlier observation, made with normal islets, of a fast onset of desensitization, thus diminishing the loss of granules. ${ }^{732}$ Remarkably, the slight reduction of the submembrane granule number as seen by TIRFM fits better to the measurement of insulin content than the marked reduction of the granulation state as reported by electron microscopy. ${ }^{47}$

While a continuous flow of granules from the transGolgi network to plasma membrane undoubtedly exists, ${ }^{26}$ the computerized mobility analysis of the entirety of submembrane granules revealed that the large majority of the granules arriving at the plasma membrane do not get attached but return to the inner space after varying periods of residence. ${ }^{18} 33$ Of note, the cell interior as seen by TIRFM is defined by the limits of the evanescent wave. Typically, the decay constant $(1 / \mathrm{e}=37 \%)$ is in the range of $50-100 \mathrm{~nm}$, thus a distance of approximately $250 \mathrm{~nm}$ or one granule diameter ${ }^{34}$ can be assumed for the granule fluorescence to entirely disappear before possible reappearance.

This bidirectional movement is reflected to different degrees by three parameters: the cumulative granule number, the number of arrivals (at the plasma membrane or, rather, the TIRF plane) and the number of short termresident granules. ${ }^{182}$ In contrast to the granule number that gives a snapshot, the cumulative granule number sums up all identified granules per image sequence. Since this number increases with increasing sequence length and may reach 10000 granules within a minute, which is the estimated number of the entire content of the beta cell, ${ }^{34-36}$ it has to be concluded that the granules recirculate. The faster the turnover is, the larger the number of arrivals and of short-term resident granules will be.

Evidenced by lower values of the above three parameters, both desensitization and rest led to a decreased turnover, in spite of the different effects on the granule number per time point. Likewise, both pretreatments increased the number of long-term residents and diminished the caging diameter, a measure of the lateral 
mobility. Since increasing periods of residence correlate with decreasing lateral mobility (see figure $3 \mathrm{~A}$, see also ref 18) both parameters are inter-related and may reflect the progression of granule tethering, a poorly understood transition process to stable granule attachment. ${ }^{37}$

However, this relation does not fully explain the diminished caging diameter, since for each period of residence, the caging diameter after either pretreatment was lower than the one of the pertaining controls. In particular, the difference between the granules after rest and control raised the question as to whether this might be due to the different age of the granule population (see further).

TIRFM of the granules undergoing exocytosis has shown that in addition to pre-existent granules (which or may not be docked) also newly arrived granules were involved. ${ }^{38-40}$ In our investigations, such events were rare. More than $90 \%$ of the exocytoses during one sequence were caused by pre-existent granules. ${ }^{18}$ Since the sequence duration is only $25 \mathrm{~s}$, this does not necessarily mean that such granules are docked and primed. Earlier, we identified a small caging diameter as a feature that distinguishes the pre-exocytotic granules from the bulk of near-membrane granules. ${ }^{18}{ }^{22}$ Since the longterm residents have the smallest caging diameter of the submembrane granules (see figure 3A), a high number of long-term residents may predispose to an increased fusion probability.

In spite of this common precondition after desensitization and rest, the number of exocytotic events differed. The lower number after desensitization and the higher number after rest correlated with the secretion as measured with statically incubated single MIN6 cells. Perifusion of MIN6 pseudoislets unexpectedly showed that the KCl-induced secretion after rest was not significantly different from control but was still significantly stronger than after desensitization. With pseudoislets, a significant response to glucose was seen under all three conditions, but the response to glucose was more sluggish after either pretreatment. This raises the question as to whether the lower rate of granule arrivals (see figure $2 \mathrm{~A}, \mathrm{~B}$ ) may be relevant for this feature.

A major reason for the more impressive effect of rest on single cells than on pseudoislets may be that the latter were perifused. During the perifusion of the hIns-EGFPtransfected cells after rest, the number of submembrane granules decreased much more than control; at the same time, the difference in the proportion of short-term resident granules disappeared (see figure $2 \mathrm{~B}$ ). So, the situation established by rest may be more quickly reversible than the desensitized state. Furthermore, cell-to-cell interaction in the pseudoislet may play a role, a feature that should be kept in mind when results obtained with single beta cells are extrapolated to the function of entire islets. ${ }^{414}$

In single cells the $\left[\mathrm{Ca}^{2+}\right]_{\mathrm{i}}$ response to glucose was virtually absent in all preparations, concurrent with the lack of stimulated secretion. The $\left[\mathrm{Ca}^{2+}\right]_{\mathrm{i}}$ increase in response to $\mathrm{KCl}$ was lower after rest than after desensitization, in clear contrast to the much stronger secretory response. The conclusion that tolbutamide desensitization diminished the efficiency of the $\mathrm{Ca}^{2+}$ signal concurs with earlier observations on mouse islets and single beta cells. ${ }^{73}$ In pseudoislets, however, the pattern of $\left[\mathrm{Ca}^{2+}\right]_{i}$ after rest corresponded closely to the one of the control-cultured pseudoislets, whereas $\left[\mathrm{Ca}^{2+}\right]_{i}$ after desensitization showed an elevated basal state and diminished increases on stimulation. Here, the weak response of rested pseudoislets to glucose is not reflected by $\left[\mathrm{Ca}^{2+}\right]_{\mathrm{i}}$. In general terms, desensitization and rest modify the $\left[\mathrm{Ca}^{2+}\right]_{\mathrm{i}}$ response on subsequent stimulation, but the efficiency of the $\mathrm{Ca}^{2+}$ signal is modified as well. It remains to be clarified as to whether this involves changes in the cellular ATP content, which have been described to result from the exposure to tolbutamide. $^{44}$

Assuming a role for granule aging, DsRed E5-labeled cells were characterized, which permits to distinguish granules that are older than 18 hours from those which are younger. ${ }^{45}$ This period fits to the duration of pretreatment to desensitize or rest the MIN6 cells. The use of this label was complicated by a high rate of mistargeting, considerable intercellular heterogeneity and the slow transition from green to red fluorescence, which led to the identification of granules in both emission channels. This is the likely reason why the granule number and the cumulative granule number were higher, when green and red granules were added, than the corresponding values obtained with hIns-EGFP. The caging diameter and the relative parameters, namely short-term and longterm residents and arrivals, were, however, comparable.

Irrespective of the culture condition, young (green emitting) granules were more abundant than aged (red emitting) granules, but the ratio of young to aged was higher after desensitization than after rest. In spite of this, aged granules were more abundant among the arriving and short-term resident granules, suggesting a higher rate of arrivals and departures or, generally, a higher mobility. This conclusion is at variance with reports on reduced mobility by aged granules ${ }^{46} 47$ but concurs with the original report on the consequences of granule aging in chromaffin cells, ${ }^{48}$ where most of the aged granules showed increased mobility. In the reports on the reduced mobility of aged insulin granules, multigranular bodies with high mobility were observed, which apparently contained the remnants of multiple old granules, and it was suggested that these bodies could be mistaken for granules. ${ }^{34647}$ In view of the similar mobility pattern of young and aged granules, which is only quantitatively different, we think that aged granules frequently arrive at the plasma membrane but are less able to tether and build up a lasting presence as seen from their low number of long-term resident granules. This may be the reason for the diminished release probability of aged granules as found in chromaffin cells and recently confirmed for beta cells. ${ }^{49}$

A limitation of the present data set is that the consequences of pretreatment on the mobility pattern reported 
by hIns-DsRed E5 labeling only partially concurs with the one reported by hIns-EGFP labeling. This is likely due to the double identification of transition state (orange) granules and the different mean age of the granule populations after desensitization and rest. Nevertheless, it can be concluded that the preceding functional state of insulin-producing cells is reflected by the number, age and mobility of the submembrane granules. These factors apparently influence the granule tethering as the initial step toward exocytosis and may thus contribute to the memory of the beta cells.

Acknowledgements The authors would like to thank Verena Lier-Glaubitz and Claudia Bütefisch for skillful technical assistance. Open access was supported by funds of the library of the Technische Universität Braunschweig

Contributors BG performed experiments, analyzed and interpreted the data. DB and $\mathrm{KH}$ performed experiments and analyzed the data. IR designed the study, analyzed and interpreted the data and wrote the manuscript. All authors reviewed and approved the manuscript. IR is the guarantor of this study and, as such, had full access to all the data in the study and takes responsibility for the integrity of the data and the accuracy of the data analysis.

Funding This study was supported by the Deutsche Forschungsgemeinschaft (Ru 368/5-4) and by the Deutsche Diabetes Gesellschaft.

Competing interests None declared.

Patient consent for publication Not applicable.

Provenance and peer review Not commissioned; externally peer reviewed.

Data availability statement Data are available on reasonable request. This is fully in vitro research. The raw data are available upon reasonable request, to be directed to the corresponding author.

Supplemental material This content has been supplied by the author(s). It has not been vetted by BMJ Publishing Group Limited (BMJ) and may not have been peer-reviewed. Any opinions or recommendations discussed are solely those of the author(s) and are not endorsed by BMJ. BMJ disclaims all liability and responsibility arising from any reliance placed on the content. Where the content includes any translated material, BMJ does not warrant the accuracy and reliability of the translations (including but not limited to local regulations, clinical guidelines, terminology, drug names and drug dosages), and is not responsible for any error and/or omissions arising from translation and adaptation or otherwise.

Open access This is an open access article distributed in accordance with the Creative Commons Attribution Non Commercial (CC BY-NC 4.0) license, which permits others to distribute, remix, adapt, build upon this work non-commercially, and license their derivative works on different terms, provided the original work is properly cited, appropriate credit is given, any changes made indicated, and the use is non-commercial. See: http://creativecommons.org/licenses/by-nc/4.0/.

\section{REFERENCES}

1 Dunbar JC, Foà PP. An inhibitory effect of tolbutamide and glibenclamide (glyburide) on the pancreatic islets of normal animals. Diabetologia 1974;10:27-35.

2 Filipponi P, Marcelli M, Nicoletti I, et al. Suppressive effect of long term sulfonylurea treatment on a, B, and D cells of normal rat pancreas. Endocrinology 1983;113:1972-9.

3 Karam JH, Sanz N, Salamon E, et al. Selective unresponsiveness of pancreatic beta-cells to acute sulfonylurea stimulation during sulfonylurea therapy in NIDDM. Diabetes 1986;35:1314-20.

4 Rustenbeck I, Wienbergen A, Bleck C, et al. Desensitization of insulin secretion by depolarizing insulin secretagogues. Diabetes 2004:53:S140-50.

5 Anello M, Gilon P, Henquin JC. Alterations of insulin secretion from mouse islets treated with sulphonylureas: perturbations of $\mathrm{Ca} 2+$ regulation prevail over changes in insulin content. Br J Pharmacol 1999;127:1883-91.

6 McClenaghan NH, Ball AJ, Flatt PR. Induced desensitization of the insulinotropic effects of antidiabetic drugs, BTS 67582 and tolbutamide. Br J Pharmacol 2000;130:478-84.

7 Rustenbeck I, Winkler M, Jörns A. Desensitization of insulin secretory response to imidazolines, tolbutamide, and quinine.
I. secretory and morphological studies. Biochem Pharmacol 2001:62:1685-94.

8 Björklund A, Grill V. B-Cell insensitivity in vitro: reversal by diazoxide entails more than one event in stimulus-secretion coupling. Endocrinology 1993;132:1319-28.

9 Grill V, Björklund A. Overstimulation and beta-cell function. Diabetes 2001;50:S122-4.

10 Laedtke T, Kjems L, Pørksen N, et al. Overnight inhibition of insulin secretion restores Pulsatility and proinsulin/insulin ratio in type 2 diabetes. Am J Physiol Endocrinol Metab 2000;279:E520-8.

11 Grill V, Radtke M, Qvigstad E, et al. Beneficial effects of K-ATP channel openers in diabetes: an update on mechanisms and clinical experiences. Diabetes Obes Metab 2009;11 Suppl 4:143-8.

12 van Raalte $\mathrm{DH}$, Verchere CB. Improving glycaemic control in type 2 diabetes: stimulate insulin secretion or provide beta-cell rest? Diabetes Obes Metab 2017;19:1205-13.

13 Omar-Hmeadi M, Idevall-Hagren O. Insulin granule biogenesis and exocytosis. Cell Mol Life Sci 2021;78:1957-70.

14 Gold G, Gishizky ML, Grodsky GM. Evidence that glucose "marks" beta cells resulting in preferential release of newly synthesized insulin. Science 1982;218:56-8.

15 Michael DJ, Ritzel RA, Haataja L, et al. Pancreatic beta-cells secrete insulin in fast- and slow-release forms. Diabetes 2006;55:600-7.

16 Yasuda T, Shibasaki T, Minami K, et al. Rim2alpha determines docking and priming states in insulin granule exocytosis. Cell Metab 2010;12:117-29.

17 Guček A, Gandasi NR, Omar-Hmeadi M, et al. Fusion pore regulation by cAMP/Epac2 controls cargo release during insulin exocytosis. Elife 2019;8:e41711.

18 Schumacher K, Matz M, Brüning D, et al. Granule mobility, fusion frequency and insulin secretion are differentially affected by insulinotropic stimuli. Traffic 2015;16:493-509.

19 Brüning D, Reckers K, Drain P, et al. Glucose but not $\mathrm{KCl}$ diminishes submembrane granule turnover in mouse beta-cells. $\mathrm{J} \mathrm{Mol}$ Endocrinol 2017;59:311-24.

20 Miyazaki J, Araki K, Yamato E, et al. Establishment of a pancreatic beta cell line that retains glucose-inducible insulin secretion: special reference to expression of glucose transporter isoforms. Endocrinology 1990;127:126-32.

21 Hauge-Evans AC, Squires PE, Persaud SJ, et al. Pancreatic betacell-to-beta-cell interactions are required for integrated responses to nutrient stimuli: enhanced ${ }^{\mathrm{Ca} 2+}$ and insulin secretory responses of MIN6 pseudoislets. Diabetes 1999;48:1402-8.

22 Matz M, Schumacher K, Hatlapatka K, et al. Observer-independent quantification of insulin granule exocytosis and pre-exocytotic mobility by TIRF microscopy. Microsc Microanal 2014;20:206-18.

23 Willenborg M, Schumacher K, Rustenbeck I. Determination of betacell function: insulin secretion of isolated islets. Methods Mol Biol 2012;933:189-201.

24 Tsuboi T, Rutter GA. Insulin secretion by 'kiss-and-run' exocytosis in clonal pancreatic islet beta-cells. Biochem Soc Trans 2003;31:833-6.

25 Barg S, Eliasson L, Renström E, et al. A subset of 50 secretory granules in close contact with L-type $\mathrm{Ca} 2+$ channels accounts for first-phase insulin secretion in mouse beta-cells. Diabetes 2002;51:S74-82.

26 Rorsman P, Renström E. Insulin granule dynamics in pancreatic beta cells. Diabetologia 2003;46:1029-45.

27 Gerber SH, Südhof TC. Molecular determinants of regulated exocytosis. Diabetes 2002;51 Suppl 1:S3-11.

28 Nesher R, Cerasi E. Modeling phasic insulin release: immediate and time-dependent effects of glucose. Diabetes 2002;51 Suppl 1:S53-9.

29 Nenquin M, Szollosi A, Aguilar-Bryan L, et al. Both triggering and amplifying pathways contribute to fuel-induced insulin secretion in the absence of sulfonylurea receptor-1 in pancreatic beta-cells. $J$ Biol Chem 2004;279:32316-24.

30 Gold G, Pou J, Gishizky ML, et al. Effects of tolbutamide pretreatment on the rate of conversion of newly synthesized proinsulin to insulin and the compartmental characteristics of insulin storage in isolated rat islets. Diabetes 1986;35:6-12.

31 Uchizono Y, Alarcón C, Wicksteed BL, et al. The balance between proinsulin biosynthesis and insulin secretion: where can imbalance lead? Diabetes Obes Metab 2007;9 Suppl 2:56-66.

32 Rustenbeck I. Desensitization of insulin secretion. Biochem Pharmacol 2002;63:1921-35.

33 Hatlapatka K, Matz M, Schumacher K, et al. Bidirectional insulin granule turnover in the submembrane space during $\mathrm{K}(+)$ depolarization-induced secretion. Traffic 2011;12:1166-78.

34 Müller A, Mziaut $\mathrm{H}$, Neukam M, et al. A 4D view on insulin secretory granule turnover in the $\beta$-cell. Diabetes Obes Metab 2017;19 Suppl 1:107-14. 
35 Dean PM. Ultrastructural morphometry of the pancreatic -cell. Diabetologia 1973;9:115-9.

36 Olofsson CS, Göpel SO, Barg S, et al. Fast insulin secretion reflects exocytosis of docked granules in mouse pancreatic B-cells. Pflugers Arch 2002;444:43-51.

37 Valero V, Nevian T, Ho D, et al. Tethering forces of secretory granules measured with optical tweezers. Biophys J 2008;95:4972-8.

38 Ohara-Imaizumi M, Fujiwara T, Nakamichi Y, et al. Imaging analysis reveals mechanistic differences between first- and second-phase insulin exocytosis. J Cell Biol 2007;177:695-705.

39 Shibasaki T, Takahashi H, Miki T, et al. Essential role of Epac2/Rap1 signaling in regulation of insulin granule dynamics by cAMP. Proc Natl Acad Sci U S A 2007;104:19333-8.

40 Izumi T. Heterogeneous modes of insulin granule exocytosis: molecular determinants. Front Biosci 2011;16:360-7.

41 Almaça J, Liang T, Gaisano HY, et al. Spatial and temporal coordination of insulin granule exocytosis in intact human pancreatic islets. Diabetologia 2015;58:2810-8.

42 Gan WJ, Do OH, Cottle L, et al. Local integrin activation in pancreatic $\beta$ cells targets insulin secretion to the vasculature. Cell Rep 2018;24:2819-26.
43 Rustenbeck I, Dickel C, Grimmsmanns T. Desensitization of insulin secretory response to imidazolines, tolbutamide, and quinine. II. electrophysiological and fluorimetric studies. Biochem Pharmacol 2001;62:1695-703.

44 Panten U, Zünkler BJ, Scheit S, et al. Regulation of energy metabolism in pancreatic islets by glucose and tolbutamide. Diabetologia 1986;29:648-54.

45 Terskikh A, Fradkov A, Ermakova G, et al. "Fluorescent timer": protein that changes color with time. Science 2000;290:1585-8.

46 Ivanova A, Kalaidzidis Y, Dirkx R, et al. Age-Dependent labeling and imaging of insulin secretory granules. Diabetes 2013;62:3687-96.

47 Hoboth P, Müller A, Ivanova A, et al. Aged insulin granules display reduced microtubule-dependent mobility and are disposed within actin-positive multigranular bodies. Proc Natl Acad Sci U S A 2015;112:E667-76.

48 Duncan RR, Greaves J, Wiegand UK, et al. Functional and spatial segregation of secretory vesicle pools according to vesicle age. Nature 2003;422:176-80.

49 Yau B, Hays L, Liang C, et al. A fluorescent timer reporter enables sorting of insulin secretory granules by age. J Biol Chem 2020;295:8901-11. 